\title{
Determination of Volume of Alaska Pollock (Theragra chalcogramma) by Image Analysis
}

\author{
MURAT O. BALABAN, ${ }^{1}$ MELANIE CHOMBEAU, ${ }^{2}$ BAHAR \\ GÜMÜŞ, ${ }^{3}$ AND DILŞAT CIRBAN ${ }^{4}$ \\ ${ }^{1}$ Fishery Industrial Technology Center, University of Alaska Fairbanks, School of \\ Fisheries and Ocean Sciences, Kodiak, Alaska, USA \\ ${ }^{2}$ Agricultural Engineering School, ESITPA, Mont Saint Aignan, France \\ ${ }^{3}$ School of Fisheries, Akdeniz University, Antalya, Turkey \\ ${ }^{4}$ Izmir Institute of Technology, Urla, Izmir, Turkey
}

\begin{abstract}
The objective of this study was to develop two methods to predict the volume of whole Alaska pollock and to compare the results with the experimentally measured volumes. One hundred fifty-five whole pollock, obtained from a Kodiak processor, were individually immersed in a graduated cylinder equipped with an outflow tube to catch the displaced water as a result of immersion. The weight of the water was recorded. Then the fish were placed in a light box equipped with a digital video camera, and the side view and top view recorded (2 images for each fish). A reference square of known surface area was placed by the fish. A cubic spline method to predict volume by integration of cross-sectional area slices based on the top and side views and an empirical equation using dimensional (length $L$, width $W$, depth $D$ ) measurements at three locations of the fish image were developed. The $R^{2}$ value for the correlation between the $L \times W \times D$ versus measured volume was 0.987 . The best $R^{2}$ for the correlation of the predicted volume by the cubic spline method versus the measured volume was 0.99. Image analysis can be used reliably to predict the volume of whole Alaska pollock.
\end{abstract}

Keywords image analysis, volume prediction, Alaska pollock, cubic splines

\section{Introduction}

Pollock is a semipelagic schooling fish widely distributed in the North Pacific Ocean with largest concentrations found in the eastern Bering Sea. Alaska pollock (Theragra chalcogramma) supports a large and important commercial fishery in the United States. Harvesting and processing Alaska pollock have become economically significant aspects of the fishing industry in Alaska. This is one of the world's largest fisheries and, during 2008, made up 59.8\% of the average ground fish catch off the coast of Alaska. The pollock catch for 2008 was 1.04 million metric tons, down approximately $26 \%$ from 2007 (National Marine Fisheries Service-NOAA Fisheries, 2008).

The authors would like to thank Westwards Seafoods, Inc.- especially Mr. Hiroyuki Kozuma, Vice President of Operations; Mr. Mitch Kilborn, General Manager; and Mr. Chris Sannito, QC Manager-for allowing the use of their plant and their fish for the study. Partial funding was provided by the University of Alaska Fairbanks.

Address correspondence to Murat O. Balaban, 118 Trident Way, Kodiak, AK, 99615. USA. E-mail: mob@sfos.uaf.edu 
Most foods and agricultural materials have non-uniform shapes and present challenges in the prediction of their volume. For non-porous materials, immersion in a liquid is a reliable measurement of volume. Laser scanning has been used to predict cross-sectional areas and, therefore, volume by their integration. This method is used for portioning/deboning of fish (Dansk Teknologi, Alleroed, Denmark; Marel, Gardabaer, Iceland).

Instead of measuring the 3D shape of strawberries with a laser scanner, Imou et al. (2006) developed a method of using nine mirrors placed around the object and taking simultaneous images of the side views with a digital camera. A volume intersection method was developed to calculate the volume. They reported that positional root mean square errors in the reconstructed contours were $0.5-2 \mathrm{~mm}$ for the tested samples.

An image analysis method was developed to measure volume and surface area of ellipsoidal foods such as eggs, lemons, limes, and peaches (Sabliov et al., 2002). The method assumed that each product had an axi-symmetric geometry and was a sum of superimposed elementary frustums of right circular cones. The dimensions of the individual frustums were determined using a digitized picture of the product. They reported that the volume and surface areas computed showed good agreement with analytical and experimental results.

Kuensting et al. (2002) developed an image analysis method involving volume rendering of thin slice microscopy images to display the 3D representation of soybeans for visualization. Characteristics of mature dry barley grain were measured by image analysis to predict its malting quality (Garcia del Moral et al., 1998).

An apparatus for 3D measurement with a structured light system was made to study the shape of soybean seed; its axial length, surface area, volume, particle density, compactness, and sphericity were measured; and typical size and shape of seed were calculated (Sakai and Yonekawa, 1991).

In the aquatic foods area, Odone et al. (1998) developed a support vector machine combined with a vision system to estimate fish weight from sets of morphometric measurements. The method was tested on 99 trout between 300 and $600 \mathrm{~g}$, showing good accuracy and reliability. Clausen et al. (2007) developed a method to extract weight distribution of the fish within fish cages from captured images. This is becoming very important in aquaculture, especially for large fish. They reported that lighting was critical, and resolution of overlapping objects depended on the density of the fish.

Fish length and orientation were measured using an online method to differentiate between flatfish and round fish (100\% accuracy) and sorting by species at $99.8 \%$ reliability (Svellingen et al., 2006; White et al., 2006) using a digital camera and image processing techniques. A standard deviation of $1.2 \mathrm{~mm}$ was obtained when measuring fish length. An extension of this would be to determine the weight/volume of the fish.

View area obtained from image analysis has been correlated to weight of shrimp (Luzuriaga et al., 1997), salmon (Balaban et al., 2010), trout (Gümüş and Balaban, 2010), and oysters (Damar et al., 2006). In the estimation of volume of non-homogeneous foods of irregular shape, such as oysters, a method based on cubic splines was developed (Damar et al., 2006). Good correlations between predicted and measured volumes were found for oysters from different regions.

The objective of this study was to test two methods to predict the volume of Alaskan pollock. The first method used dimensional measurement from images and correlated them to experimental volume. The second method used the cubic splines technique (Damar et al., 2006) and adapted it to Alaskan pollock images. The accuracy of volume predictions were compared with experimentally measured volumes. 


\section{Material and Methods}

\section{Fish Samples}

One hundred and fifty-one Alaskan pollock (Theragra chalcogramma) were used for this study. They were obtained fresh, within 2 days after catch, from a Kodiak processing plant. They were taken randomly by the plant staff from the process line in order to have a wide spectrum of different size fish.

\section{Weighing, Measuring the Volume, and Imaging}

A Mettler Toledo PB 3002-S (Columbus, OH, USA) balance with a maximum capacity of $3100 \mathrm{~g}$ and an accuracy of $0.1 \mathrm{~g}$ was used. Each pollock was weighed and immersed in a graduated cylinder to collect the displaced water and deduce the volume by weighing the net weight of water.

The fish was then placed in a light box designed and built by the researchers (Luzuriaga et al., 1997), with the dimensions $124.5-\mathrm{cm}$ high, 66-cm deep, and 86-cm wide. Fluorescent bulbs providing D65 illumination were used behind a translucent Polycast acrylic (No. 2447, Polycast Technology Corp., Stanford, CT, USA) 6.35-mm thick with 51\% light transmission. The door of the light box was closed during picture-taking to eliminate interference from ambient light.

A Nikon D200 SLR digital camera (Nikon Corp., Tokyo, Japan) with a Nikon AF-S 18-200 mm F/3.5-5.6G ED-IF AF DX VR lens was used to take both the side view and the top view images of each fish (Figure 1). All adjustments of the camera were set to "manual" for repeatability of pictures. The Nikon WT-3 wireless accessory was used to control the camera remotely from a laptop computer and to transfer the images to the computer immediately after acquisition using the Nikon Camera Control Pro software (Nikon Corp., Tokyo, Japan). The camera was mounted on a Bogen-Manfrotto Maxi Repro Stand Lite assembly (Bogen Imaging, Inc., Ramsey, NJ, USA) with the lens looking downward. This setup was placed inside the light box. A reference square of $5 \mathrm{~cm} \times$ $5 \mathrm{~cm}$ was used as a calibration for size in every image by placing it in the light box for every shot.

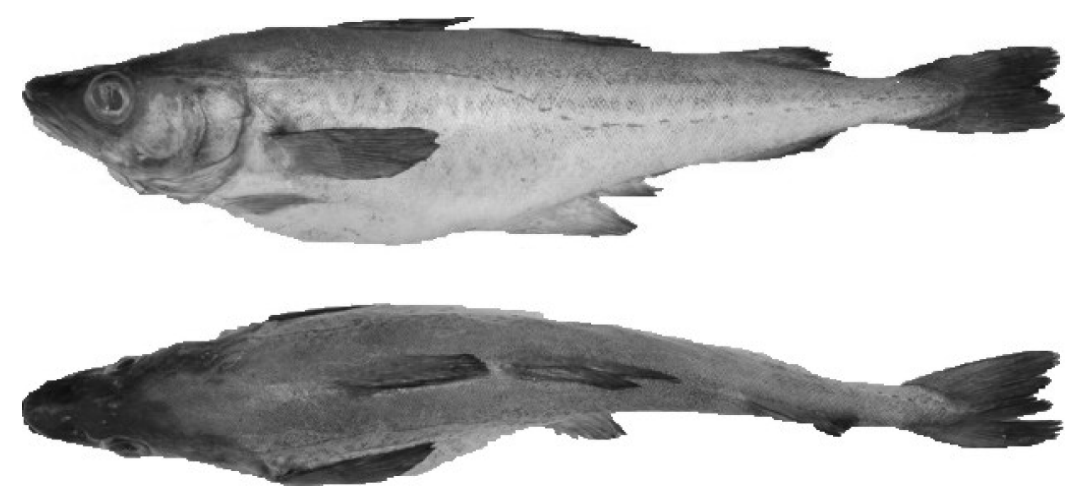

Figure 1. Typical image of side view and top view of Alaskan Pollock. 


\section{Measurements of Dimensions}

A computer program was developed in Visual Basic to measure lengths in centimeters based on the reference square on the image. The images used were manually modified to erase the fins and the tail. An example of measurements of length (L), width (W), and depth (D) are shown in Figure 2. These dimensions were multiplied, and a correlation of the form:

$$
\text { Volume }\left(\mathrm{cm}^{3}\right)=\mathrm{A} \times \mathrm{L} \times \mathrm{W} \times \mathrm{D}
$$

was developed. The parameter A was found by linear regression. In order to assess the error in the measurement, the same person who did all the measurements on the images replicated the measurements on the same fish image 5 times at the beginning of the analyses, 5 times at the midpoint of the analyses, and 5 times at the end of the analyses. The results are given in Table 1. The maximum deviation in the measurement of the reference square was $0.74 \%$. The maximum measurement deviation in the 3 dimensional measurements was $1.91 \%$. Therefore, the accuracy of the dimensional measurements was assumed as acceptable.

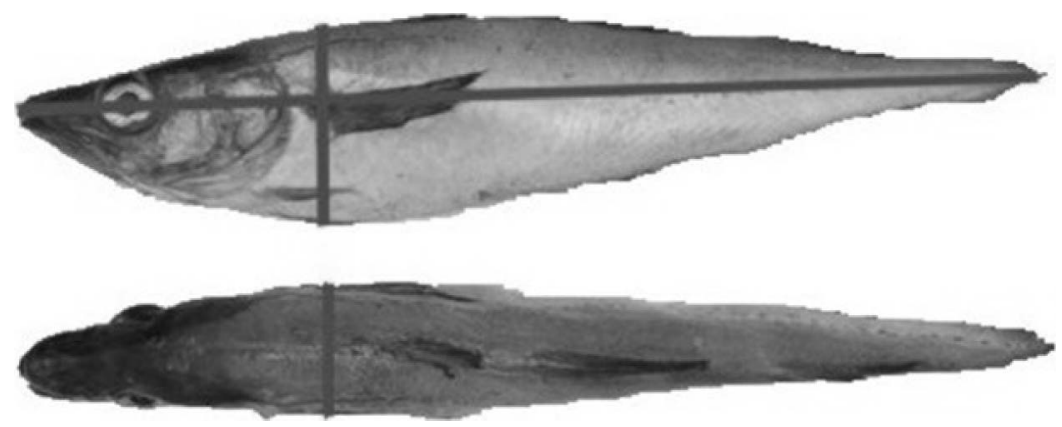

Figure 2. Dimensional measurements on the image: length (L), width (W), and depth (D).

Table 1

Analysis of measurement error from the dimensional measurements on the fish images

\begin{tabular}{|c|c|c|c|c|c|c|c|c|}
\hline & & $\begin{array}{l}\text { Reference } \\
\text { square } \\
\text { (pixels) }\end{array}$ & $\begin{array}{c}\mathrm{L} \\
\text { (pixels) }\end{array}$ & $\begin{array}{l}\mathrm{L} \\
(\mathrm{cm})\end{array}$ & $\begin{array}{c}\mathrm{W} \\
\text { (pixels) }\end{array}$ & $\mathrm{W}(\mathrm{cm})$ & $\begin{array}{c}\mathrm{D} \\
\text { (pixels) }\end{array}$ & $\begin{array}{l}\mathrm{D} \\
(\mathrm{cm})\end{array}$ \\
\hline \multirow{3}{*}{$\begin{array}{l}\text { Before the } \\
\text { analyses }\end{array}$} & Average & 61.20 & 642.26 & 52.47 & 132.62 & 10.84 & 107.89 & 8.82 \\
\hline & St. dev. & 0.45 & 0.90 & 0.41 & 2.19 & 0.21 & 0.46 & 0.10 \\
\hline & $\%$ deviation & 0.73 & 0.14 & 0.79 & 1.65 & 1.91 & 0.43 & 1.15 \\
\hline \multirow{3}{*}{$\begin{array}{l}\text { At midpoint } \\
\text { during } \\
\text { analyses }\end{array}$} & Average & 60.80 & 644.10 & 52.97 & 132.04 & 10.86 & 108.51 & 8.92 \\
\hline & St. dev. & 0.45 & 1.13 & 0.43 & 1.39 & 0.14 & 1.06 & 0.10 \\
\hline & $\%$ deviation & 0.74 & 0.18 & 0.82 & 1.05 & 1.29 & 0.98 & 1.13 \\
\hline \multirow{3}{*}{$\begin{array}{l}\text { At the end of } \\
\text { analyses }\end{array}$} & Average & 61.01 & 644.50 & 52.82 & 133.63 & 10.95 & 107.28 & 8.79 \\
\hline & St. dev. & 0.01 & 1.26 & 0.09 & 2.08 & 0.17 & 1.59 & 0.13 \\
\hline & $\%$ deviation & 0.02 & 0.19 & 0.17 & 1.55 & 1.56 & 1.48 & 1.49 \\
\hline
\end{tabular}

$n=5$ for each analysis. 

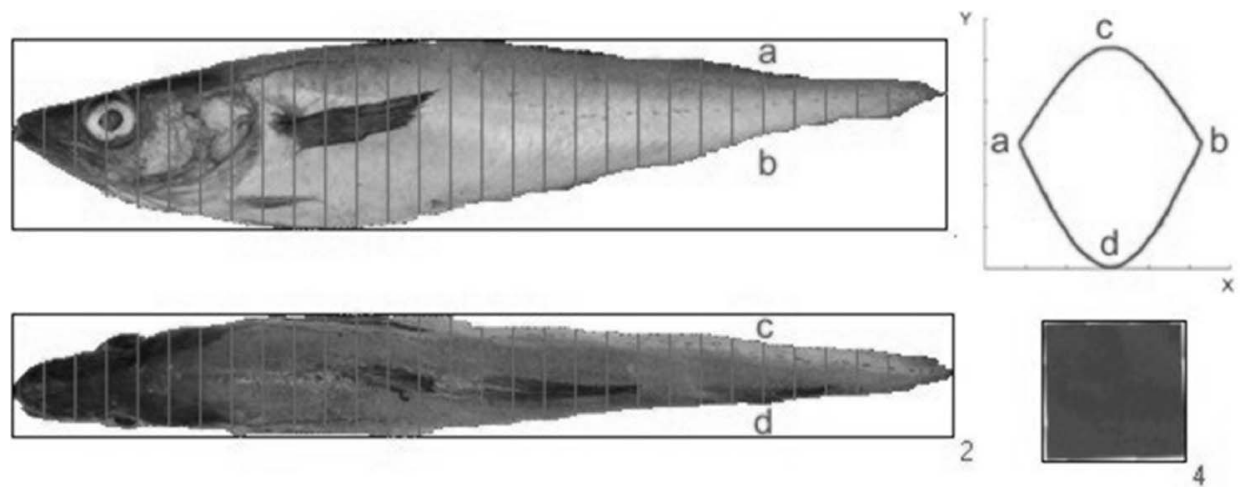

Figure 3. Calculation of cross-sectional areas using the cubic splines method. The size reference square is also shown.

\section{Cubic Spline Method}

The side and top views of the fish were used together. First, the fish was divided into an even number of equal sections. Coordinates of points a, b, c, and d were determined (Figure 3). Points $\mathrm{c}$ and $\mathrm{d}$ are assumed to be in the middle of points a and b, along the $\mathrm{X}$ axis. Therefore:

$$
c_{x}=\frac{a_{x}+b_{x}}{2} \quad d_{x}=c_{x}
$$

The cross-sectional area at each section was found by fitting one cubic spline to points a, c, and b and another to points a, d, and b (see right-hand side of Figure 3). The crosssectional area formed by these two curves was calculated as:

$$
\text { Cross sectional area }=\frac{5\left(b_{x}-a_{x}\right)\left(d_{y}-c_{y}\right)}{8}
$$

The areas bounded by cross-sectional splines were calculated by a closed form equation developed for this application. These cross-sectional areas were then integrated along the $\mathrm{Z}$ axis using Simpson's method:

$$
\text { Volume }=\frac{h}{3} \sum_{i=\text { odd }}^{n} 4 \text { area }_{i}+\sum_{i=\text { even }}^{n} 2 \text { area }_{i}
$$

where $\mathrm{n}$ : number of cross sections and $\mathrm{h}=($ length $) / \mathrm{n}$. Up to 30 sections were tried, and the average volume resulting from 20 sections to 30 sections was used. The effect of the number of divisions for a typical fish is shown in Figure 4. To evaluate if the maximum number of divisions gives the most accurate result, the volume predicted by the 30 divisions was also compared with the experimentally measured volume.

\section{Results and Discussion}

The correlation between $\mathrm{L} \times \mathrm{W} \times \mathrm{D}$ and measured volume is shown in Figure 5. Once this regression line is established, the volume of the fish is predicted by using the L, W, and D measurements for individual fish. These predictions are shown in Figure 6. It is 


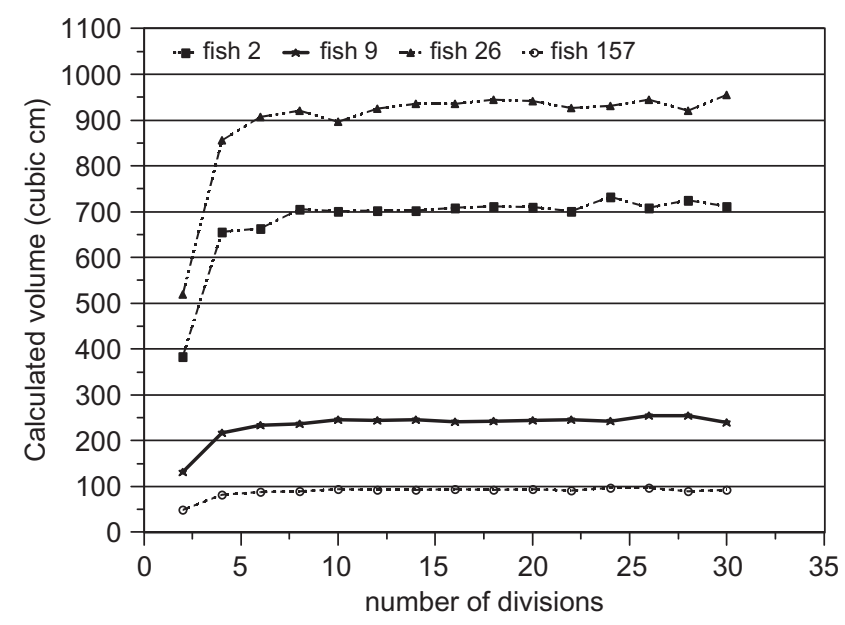

Figure 4. Variations of the volume calculated by cubic splines, depending on the number of divisions used. Small and large fish are given as examples.

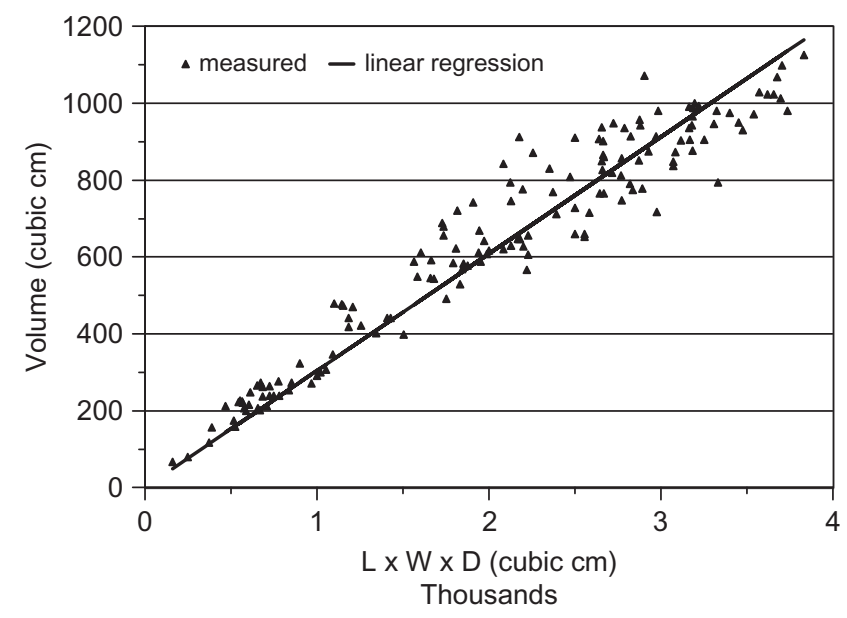

Figure 5. Correlation of $\mathrm{L} \times \mathrm{W} \times \mathrm{D}$ product with measured volume.

apparent that for small fish the prediction of volume is smaller than measured volume. This is expected since the fins and tail make up a significant volume component of small fish. For fish larger than about $600 \mathrm{~g}$, the prediction is spread on both sides of the 45-degree line (Figure 6).

The cubic spline method was sensitive to the position of the fish in the image. In some fish the mouth was open. The software did not take into account the empty area of the open mouth (Figure 7), but considered that volume as part of the volume of the fish, and therefore overestimated. It is also apparent that the small fish are more sensitive to the removal of the fins and tail from the volume consideration by the cubic spline method. For fish larger than $600 \mathrm{~g}$, this was not an issue (Figure 6). 


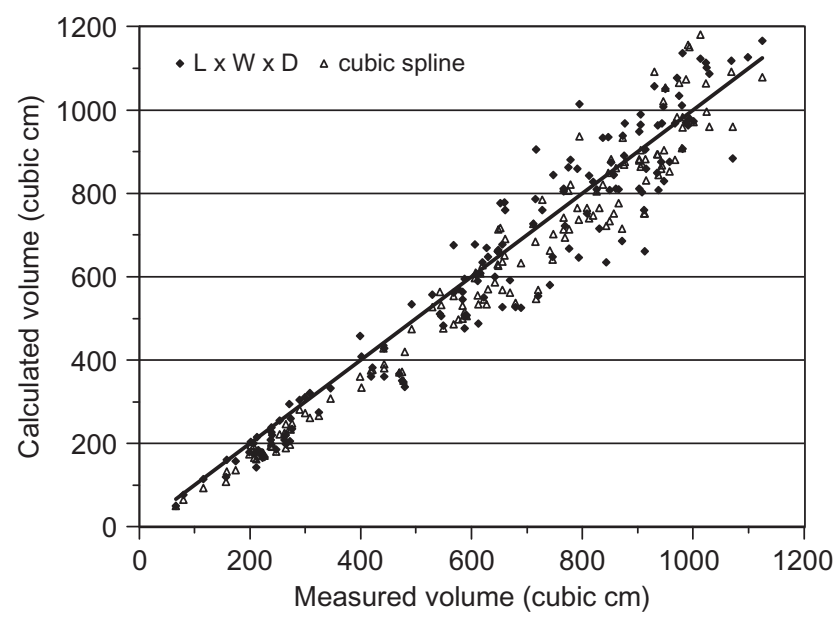

Figure 6. Comparison of volume predictions by the two methods (Y axis) with measured volume ( $\mathrm{X}$ axis). The 45-degree line is also shown.
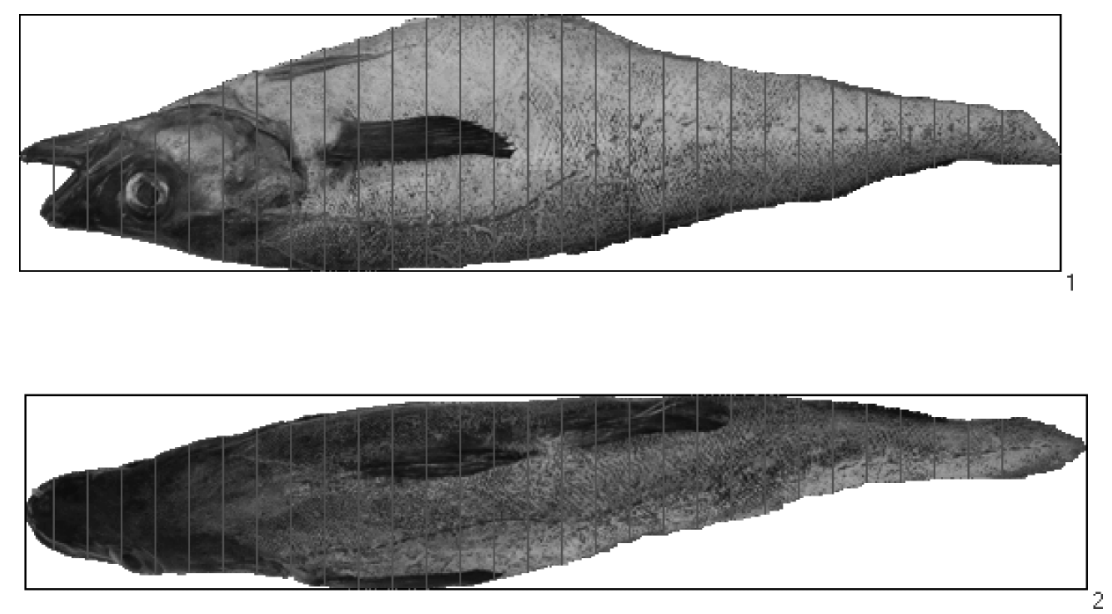

Figure 7. Source of error in cubic splines volume prediction. The open mouth of the fish results in overprediction of the volume.

There was a small improvement of the $R^{2}$ of the regression between the averages of 20 to 30 divisions in calculating the cubic splines volume (0.988) and that of taking only 30 divisions (0.99; Table 2). At least for these fish, time and effort could be saved by using only 30 divisions for the calculation of cubic splines volume.

It appears that although its $R^{2}(0.987)$ is slightly lower than the cubic splines method, the $\mathrm{L} \times \mathrm{W} \times \mathrm{D}$ method is less sensitive to the open mouth of the fish in the images. This method is also much simpler than the cubic splines method and requires much less time in computer calculations. Simple image manipulation techniques can be used to determine these dimensions even in the case of live fish and in underwater imaging conditions. Therefore, it appears that the $\mathrm{L} \times \mathrm{W} \times \mathrm{D}$ method should be considered for a rapid and automated determination of the weight of whole pollock. 
Table 2

Results of linear regression: LDW fit versus measured volume and cubic splines volume versus measured volume

\begin{tabular}{|c|c|c|c|}
\hline$Y=A X$ & LDW fit & $\begin{array}{l}\text { Cubic splines, } \\
\text { averages of } 20 \text { to } \\
30 \text { divisions }\end{array}$ & $\begin{array}{c}\text { Cubic splines, } 30 \\
\text { divisions only }\end{array}$ \\
\hline A & 0.304 & 0.956 & 0.963 \\
\hline$R^{2}$ & 0.987 & 0.988 & 0.990 \\
\hline Standard Error & 81.1 & 73.7 & 66.6 \\
\hline
\end{tabular}
$n=151$.

\section{References}

Balaban, M. O., Ünal-Şengör, G. F., Gil-Soriano, M., and Guillén-Ruiz, E. 2010. Using image analysis to predict the weight of Alaskan salmon of different species. J Food Sci. 75(3): E157-162.

Clausen, S., Greiner, K., Andersen, O., Lie, K.-A., Schulerud, H., and Kavli, T. 2007. Automatic segmentation of overlapping fish using shape priors. In: 15th Scandinavian Conference on Image Analysis (SCIA), LNCS 4522. Ersbøll, B. K., and Pedersen, K. S. (Eds.). Aalborg, Denmark: Springer. pp. 11-20.

Damar, S., Yağız, Y., Balaban, M. O., Ural, S., Oliveira, A. C. M., and Crapo, C. A. 2006. Prediction of oyster volume and weight using machine vision. J Aquat. Food Prod. T. 15(4): 5-17.

Garcia del Moral, L. F., Sopena, A., Montoya, J. L., Polo, P., Voltas, J., Codesal, P., Ramos, J. M., and Molina-Cano, J. L. 1998. Image analysis of grain and chemical composition of the barley plant as predictors of malting quality in Mediterranean environments. Cereal Chem. 75(5): 755-761.

Gümüs, B., and Balaban, M. O. 2010. Prediction of the weight of aquacultured Rainbow Trout (Oncorhynchus mykiss) by image analysis. J Aquat. Food Prod. T. 19(3-4): 227-237.

Imou, K., Kaizu, Y., Morita, M., and Yokoyama, S. 2006. Three-dimensional shape measurement of strawberries by volume intersection method. Trans ASAE. 49(2): 449-456.

Kuensting, H., Ogawa, Y., and Sugiyama, J. 2002. Structural details in soybeans: A new threedimensional visualization method. J. Food Sci. 67(2): 721-724.

Luzuriaga, D., Balaban, M. O., and Yeralan, S. 1997. Analysis of visual quality attributes of white shrimp by machine vision. J. Food Sci. 62(1): 1-7.

National Marine Fisheries Service-NOAA Fisheries. n.d. Walleye Pollock Research. Retrieved June 2, 2010, from http://www.afsc.noaa.gov/species/pollock.php

Odone, F., Trucco, E., and Verri, A. 1998. Visual learning of weight from shape using support vector machines. In: Proceedings of the British Machine VISION Conference, Southampton, UK. Carter, J. N., and Nixon, M. S. (Eds.). Southampton: British Machine Vision Association. pp. 469-477.

Sabliov, C. M., Boldor, D., Keener, K. M., and Farkas, B. E. 2002. Image processing method to determine surface area and volume of axi-symmetric agricultural products. Int. J. Food Prop. 5(3): 641-653.

Sakai, N., and Yonekawa, S. 1991. Three-dimensional image analysis of the shape of soybean seed. J. Food Eng. 15(3): 221-234.

Svellingen, C., Totland, B., White, D., and Jan Tore Øvredal, J. 2006. Automatic species recognition, length measurement and weight determination, using the CatchMeter computer vision system. Retrieved August 5, 2010, from http://www.imr.no/tokt/toktomtaler/okosystemtoktet/ toktdagbok_2006/the_catchmeter/en

White, D. J., Svellingen, C., and Strachan, N. J. C. 2006. Automated measurement of species and length of fish by computer vision. Fish. Res. 80(2-3): 203-210. 